\title{
Study on the Positioning Problem of Chinese International Education Major
}

\author{
Zengzhi Wang \\ Xi'an Peihua University, Xi'an, Shaanxi, 710125
}

Keywords: Chinese International Education, positioning problem, countermeasure

\begin{abstract}
Chinese International Education” is a major, and there are different understandings in the academic sciences of this major. This different understanding affects the talent training objectives and training specifications of this major. This paper argues that the discipline of "Chinese International Education" is cross-cutting and it is difficult to simply attribute it to a single subject. In this sense, it can be said that it is an "independent discipline." Its subject base is linguistics (theoretical linguistics, applied linguistics), Chinese linguistics, pedagogy, cognitive science, and modern educational techniques.
\end{abstract}

\section{Introduction}

"Chinese International Education" is a career and a profession. If this profession is not an independent discipline, then it should find its place in an existing discipline system or a certain existing discipline system. This article does not discuss "Chinese International Education" as a career. It only discusses the "Chinese International Education" as a major and its subject orientation. The issue of subject orientation involves the goal, specification, subject system, curriculum and textbook compilation of Chinese international education talents. There are some vague understandings on the subject and administrators on this issue, and there are some disputes. We have no intention of intervening in various disputes, but we have only published a hole on this issue and do some work for career development and discipline construction. The issue of subject orientation actually includes two aspects: the first is which subject or subjects should be attributed to "Chinese International Education"; the second is the theoretical basis (or supportive subject) of “Chinese International Education”. Of course, these two issues are interrelated.

\section{Correct the View of "Chinese International Education"}

What kind of "Chinese International Education" concept is a fundamental issue in Chinese international education. Lu Yuming's "The Positioning Problem of Chinese International Education Major" and "Several Problems in Chinese International Communication" are called "Chinese International Communication". "View, this problem is not solved. In fact, there is no goal or direction in Chinese international education. The vast majority of Chinese learners are unlikely to come to China. If the purpose of Chinese international education is to build a bridge of friendship for China to the world, the Chinese Bridge will greatly reduce the purpose and significance of Chinese international education. The purpose of education is not only to build a bridge of friendship to China, the Chinese Bridge, but also to serve the people who are far from the Chinese who are far away from China, so that they have a good impression of Chinese and Chinese culture, and make foreign Chinese culture Learners regard China as their second hometown and regard Chinese culture as their second spiritual home. From the perspective of the nature of language, language itself is culture, language and culture are isomorphic, that is, language is the symbol of cultural spirit and value. Language is also the carrier and symbol of the emotional and spiritual language users. From the perspective of the function of language, language, as a tool of communication and a carrier of culture, conveys emotions and thoughts, bearing cultural spirit and values. Speech is also a tool of thinking, and learning language is also the training and learning of thinking. Language is the carrier of culture, and value is the result of culture. Learning language is the study of values. These contents can be classified into the category of human spiritual home. People are people of 
language and people of culture. People have the first spiritual home, but they can also have the second spiritual home. The purpose of Chinese international education is actually and essentially the construction of the second spiritual homeland with Chinese culture as the destination. This is the "Chinese international education" concept that we should establish. Lu Yuming's so-called bridge of friendship to China is just a bridge leading to a bridge to the second spiritual home that is based on Chinese culture.

\section{The Core Task of Chinese International Education}

There is a difference between Chinese international teaching and Chinese international education. First of all, Chinese international teaching is based on classroom teaching, while Chinese international education includes not only classroom teaching, but also other educational methods other than classroom teaching. Secondly, Chinese international teaching only focuses on teaching and learning, and the scope of education is significantly larger than teaching. Thirdly, Chinese international teaching is actually the product of exam-oriented education. In fact, it is what to teach. If it is teaching, then there must be a syllabus, a model, a standard, and it is inevitable to ignore the personality of the students. It is impossible to teach according to their aptitude; Chinese international education may have greater flexibility and selectivity. It is possible to fully develop the individuality of students. It is possible to teach students in accordance with their aptitude. It may not be in accordance with the outline, not according to a model, and not subject to a standard for Chinese international education. It can be seen that the scope of Chinese international education is obviously larger than that of Chinese international teaching. Therefore, the so-called Chinese international teaching proposed by Lu Yuming's "Several Questions in Chinese International Communication" is one-sided and is not conducive to the development of Chinese international education. . Before there is no better formulation, the use of Chinese international education is obviously superior to the so-called Chinese international teaching proposed by Lu Yuming. Regarding the core tasks of Chinese international education, first of all, the problems in Chinese language and writing are mostly related to culture. It is wrong to confront the problems in Chinese language and culture with culture. It is necessary to combine Chinese language teaching with cultural teaching, and take cultural teaching as the leading factor to promote Chinese language teaching. So even if learners are temporarily unable to master the content of Chinese language teaching, learners receive Chinese culture to varying degrees. The edification has a good impression and yearning for China. Even if the content of Chinese language teaching has not yet been learned, as learners have a good impression and yearning for China, and have further interest in learning, they can learn slowly in the future. If the learner does not accept the education of Chinese language teaching led by cultural teaching at the beginning, it is not influenced by Chinese culture, and it does not have a good impression and yearning for China. This education can basically be said to have failed; if the learner is without the influence of Chinese culture, I suffered from the frustration of learning Chinese, one of the most difficult languages in the world, and lost interest in further study. Then, this education can be said to have completely failed. Secondly, it is plausible to learn and master Chinese as soon as possible in the shortest time. In the shortest time, learn and master Chinese as soon as possible. This degree of Chinese can only be a degree of survival in Chinese. For a very small number of people who come to China, this degree does not make much sense for the vast majority of those who cannot come to China. Emphasizing that learning and mastering Chinese as quickly and best as possible in the shortest time is actually a sudden attack, which will greatly hurt the learner's interest in learning, causing boredom and lack of stamina. It is a typical mistake of quick success and quick success. A variant of education. To promote and spread Chinese as art and culture, it is mainly to make learners feel good, produce a good feeling different from Western teaching methods and language learning habits, make them interested, and have a good impression and yearning for Chinese and Chinese culture. Even if he can't use Chinese for the time being. By appreciating the appreciation of Chinese characters, the interpretation of ancient poems, ancient music and national music, students can build a fun of Chinese. Avoid intensive infusion and single-handed assault teaching or intensive teaching. Again, the so-called "the general guiding 
ideology of Chinese teaching should be - 'how to let a foreign student with a zero starting point learn and master Chinese as soon as possible in the shortest possible time"' is actually a test-oriented educational thought in Chinese international education. The reflection or variant, its harmfulness is self-evident, and it will have disastrous consequences for the Chinese international education cause.

\section{The Positioning of Cultural Education in Chinese International Education}

The question of the relationship between language and culture has always been a matter of debate. But there are two points that can basically reach a consensus. First, language is the carrier of culture. Second, the language itself is also a culture. It can be seen that the content and purpose of language education must be only cultural education, specifically humanistic quality education, specifically language and literature education. Without cultural education, there is no reason why language education can spread. Chinese culture will cause resentment and uneasiness in some countries? One of the reasons for this is that there are problems with the way Chinese culture is spread. Naked cultural output should be avoided. As Zhao Jinming said, education should be quiet and silent, and it should be deaf and subtle. In this case, how can we spread Chinese culture to do this? Only literature can do this, that is, unswervingly follow and adhere to the concept of language through literature promotion and culture through literature communication. All in all, it is to change the concept, keep pace with the times, and integrate with the most advanced international language promotion and cultural communication concepts and models, and strive to make Chinese language learners and Chinese cultural learners truly take Chinese literature as their cross. Cultural exchanges and a treasure trove of acquired heterogeneous cultures. In the process of Chinese language promotion and Chinese cultural external communication, Chinese literature is the main tool and main teaching content. Teachers who study and study Chinese literature are used as Chinese language promotion and Chinese culture. The main faculty of the external communication agency, thus avoiding naked cultural output, avoiding blunt grammatical infusion and boring cultural indoctrination. The promotion of Chinese language and the transformation of Chinese culture's external communication concept will inevitably lead to the reform of its scientific research. Grammar and linguistics can no longer be used as the focus and main research direction in scientific research, but should focus on literature.

The promotion of Chinese language and the transformation of Chinese culture's external communication concept will inevitably lead to teaching reform. In the teaching concept, avoid the traditional mode of classroom teaching, use all available materials, means and occasions for teaching. The pronunciation, grammar and vocabulary must be subordinate to literature or humanities education. In the construction of teaching materials, we thoroughly reformed the textbook model with language and culture as the core content, and used literature as the core content of Chinese textbooks for foreigners. Voice, grammar, and vocabulary must be subordinate to literary or humanistic education in order to make the textbook interesting and interesting. In the classroom teaching, avoid the current rigid and unchanging routines and modes, and organize classroom teaching flexibly. In the construction of the teaching staff, it is necessary to use the literary teachers as the main body of the Chinese language teachers, and fundamentally solve the boring problem of teaching Chinese as a foreign language. Ji Xianlin's so-called "the first thing to teach foreign Chinese learners is Chinese itself" is debatable. The first thing that can be taught to foreign Chinese learners is the Chinese itself. Chinese itself is one of the most difficult languages in the world. Therefore, it is necessary to teach foreign Chinese learners about the relevant situation of Chinese. Lu You's "Zhizi" Cloud: "The result is that you want to learn poetry and work outside the poem." Learning Chinese requires more and more effort in cultures other than Chinese. It is impossible to learn anything in a single language and in any single language. Mao Zedong's "Practice Theory": "You have to know the taste of pears, you have to change the pears and eat them." Mao Zedong's theory has a certain influence in the world. Many foreign Chinese learners know, but they are not What is known through Chinese is not known by directly reading the Selected Works of Mao Zedong. In the end, I always want to eat pears, but it is very important and 
meaningful to introduce such pears first, so that learners can have saliva, good feelings and interest.

\section{Conclusion}

Chinese should become the preferred foreign language of all countries and become a strong language of the world. What is important is that our country must be strong, especially in the forefront of the economy, science and technology and education. I think that once our country can invest in countries around the world, open factories or enterprises, the staff recruited must meet Chinese requirements; once each country wants to develop its own science and technology, it is necessary to send students to China to study abroad; once in certain scientific fields In particular, in the field of natural sciences, it is not necessary to refer to academic papers written in Chinese. Once young people in various countries think about going to China to study or work, then young people from all over the world naturally use Chinese as their preferred foreign language. That's like English.

\section{References}

[1] Lu Yuming. The Positioning Problem of Chinese International Education Major [J]. Language Teaching and Research, 2014, (2): 1-16.

[2] Lu Yuming. Several Issues in Chinese International Communication [J]. Chinese Teaching and Research, 2013, (3): 1-4.

[3] Li Lingyan. Analysis and Thinking of Overseas Chinese Teaching Teachers under the Background of Chinese International Promotion [J]. Language Application, 2006(S1): 76 - 82.

[4] Li Xiaoqi. Knowledge structure for the construction of teachers in the international promotion of Chinese language [J]. Journal of Yunnan Normal University, 2007(5): 85 - 89.

[5] Chen Qingni. On the Curriculum Setting of Master's Degree in Chinese International Education [J]. Journal of Qujing Normal University. 2008(5): 117 - 122. 